\title{
Cyclic Ketones as Future Fuels: Reactivity with OH Radicals
}

\author{
Dapeng Liu, Binod Raj Giri*, Aamir Farooq*
}

King Abdullah University of Science and Technology, Clean Combustion Research Center,

Physical Sciences and Engineering Division, Thuwal 23955-6900, Saudi Arabia

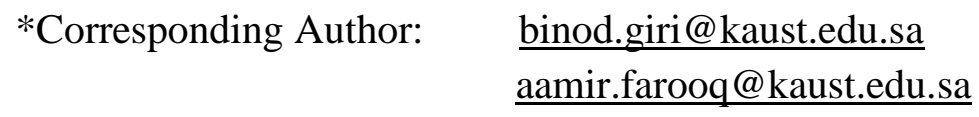




\begin{abstract}
For a sustainable energy future, research directions should orient towards exploring new fuels suitable for future advanced combustion engines to achieve better engine efficiency and significantly less harmful emissions. Cyclic ketones, among bio-derived fuels, are of significant interest to the combustion community for several reasons. As they possess high resistance to auto-ignition characteristics, they can potentially be attractive for fuel blending applications to increase engine efficiency and also to mitigate harmful emissions. Despite their importance, very few studies are rendered in understanding of the chemical kinetic behavior of cyclic ketones under engine-relevant conditions. In this work, we have conducted an experimental investigation for the reaction kinetics of $\mathrm{OH}$ radicals with cyclopentanone (CPO) and cyclohexaneone $(\mathrm{CHO})$ for the first time over a wide range of experimental conditions $(T=900$ $-1330 \mathrm{~K}$, and $p \sim 1.2$ bar) in a shock tube. Reaction kinetics was followed by monitoring UV laser absorption of $\mathrm{OH}$ radicals near $306.7 \mathrm{~nm}$. Our measured rate coefficients, with an overall uncertainty $(2 \sigma)$ of $\pm 20 \%$, can be expressed in Arrhenius form as (in units of $\mathrm{cm}^{3}$ molecule $\mathrm{s}^{-1}$ 1):

$$
\begin{array}{ll}
k_{1}(\mathrm{CPO}+\mathrm{OH})=1.20 \times 10^{-10} \exp \left(-2115 \frac{K}{T}\right) & (902-1297 \mathrm{~K}) \\
k_{2}(\mathrm{CHO}+\mathrm{OH})=2.11 \times 10^{-10} \exp \left(-2268 \frac{K}{T}\right) & (935-1331 \mathrm{~K})
\end{array}
$$
\end{abstract}

Combining our measured data with the single low-temperature literature data, the following three-parameter Arrhenius expressions (in units of $\mathrm{cm}^{3}$ molecule $\mathrm{s}^{-1}$ ) are obtained over a wider temperature range:

$$
\begin{aligned}
& k_{1}(\mathrm{CPO}+\mathrm{OH})=1.07 \times 10^{-13}\left(\frac{T}{300 K}\right)^{3.20} \exp \left(1005.7 \frac{K}{T}\right) \\
& k_{2}(\mathrm{CHO}+\mathrm{OH})=3.12 \times 10^{-13}\left(\frac{T}{300 K}\right)^{2.78} \exp \left(897.5 \frac{K}{T}\right)
\end{aligned}
$$

Discrepancies between the theoretical and current experimental results are observed. Earlier theoretical works are found to over-predict our measured rate coefficients. Interestingly, these cyclic ketones exhibit similar reactivity behavior as that of their linear ketone counterparts over the experimental conditions of this work. 


\section{Introduction}

As the global energy portfolio stands today, it appears that petroleum-based fuels will remain primary source of energy to power industry and transportation sectors for some decades to come. The renewable sources of energy are foreseen to increase their share up to $10 \%$ by 2040. Global demand for petroleum-based fuels is rising at $\sim 1 \%$ annual rate to power internal combustion engines (ICE) in the transport sector. ${ }^{1}$ This is progressively adding up the challenges for curbing environmental pollution and greenhouse gas emission. The growing concerns over global warming and diminishing petroleum reserves have led scientists and engineers to focus on improving combustion technology, e.g., by developing new fuel-engine systems.

Recently, there is a growing interest on engine-fuel design optimization due to stringent emission regulations worldwide. ${ }^{2-6}$ At present, the trends in the development of more efficient modern spark ignition (SI) engines are moving towards increasing the compression ratio and implementing turbocharging. ${ }^{4}$ The drawback of doing so is that it may cause engine knocking, or even super-knock, as the ignition delay times (IDTs) of fuel-air mixtures drop sharply with increasing cylinder intake pressure. Therefore, fuels having high anti-knock quality are quite attractive to mitigate engine knocking events in modern SI engines. To this end, cyclic ketones are of significant interest to the combustion community because these fuels are found to have positive impacts on enhanced engine performance and low pollutant emissions. Recently, CoOptima researchers evaluated 41 blendstocks from various chemical families, e.g., hydrocarbons (alkanes, alkenes and aromatics) and oxygenates (alcohols, esters, ethers, ketones), in the Tier 2 survey to assess their potential of increasing the efficiency of future advanced SI engines. ${ }^{7-8}$ The blendstock survey "Tier 2" identified eight fuel blendstocks, one 
being cyclopentanone, meeting the merit function criteria for the detailed blendstock evaluation "Tier 3" to realize their introduction in the market by 2025-2035.

Cyclic ketones appear very promising among the various renewable bio-derived fuels. Cyclic ketones can be effectively produced via chemical and biochemical conversion technology, e.g., breaking down of lignocellulosic biomass by endophytic fungi, pyrolysis of biomass or hydrogenation of biomass derived furfural ${ }^{9-12}$. These ketones display interesting and desirable combustion characteristics as the potential candidates for alternatives to petroleumbased fuels for various reasons, such as: i) they possess high resistance to auto-ignition (RON $\sim 100)^{13}$, making it favorable for application in spark-ignition internal combustion engines ${ }^{14}$; ii) they are very effective in reducing the harmful emissions of greenhouse gases, particulate matter and soot ${ }^{15,16}$. For instance, a recent experimental study in direct injection diesel engine by Boot et al. ${ }^{15}$ found cyclohexanone performing exceptionally well for soot abatement as compared to other oxygenates such as tripropylene glycol, methyl ether and dibutyl maleate. Ethers are known to be most effective in reducing soot emission among oxygenates (see Boot el. al ${ }^{15}$ and references cited therein.); iii) they are found to be promising chemical feedstock for the synthesis of high-density fuels like polycylic alkanes which can be blended into conventional aviation fuels for increased volumetric heating values. ${ }^{17-18}$ Ketones also appear as important intermediates during the low-temperature combustion of large hydrocarbons and oxygenated fuels. Despite their importance in combustion, only few studies have been dedicated to understand the combustion behavior of cyclic ketones. ${ }^{15-16,19-26}$

Giri et al. ${ }^{23}$ recently reported experimental and theoretical rate coefficients for the thermal unimolecular decomposition of cyclopentanone (CPO). Their master equation results were consistent with the experimental results, indicating that CPO almost exclusively (> 95\%) decomposes to produce $\mathrm{CO}$ and $\mathrm{C}_{2} \mathrm{H}_{4}$. Thion et al. ${ }^{20}$ studied the oxidation kinetics of $\mathrm{CPO}$ in a jet-stirred reactor over a wide range of experimental conditions $(T=730-1280 \mathrm{~K}, p=1$ and 
$10 \mathrm{~atm}$, and equivalence ratio $(\varphi)=0.5,1$ and 2). Additionally, they performed $a b$ initio/RRKM-master equation calculations to predict rate coefficients for $\mathrm{H}$-abstraction reactions of $\mathrm{CPO}$ by important combustion species $\left(\mathrm{H}, \mathrm{OH}\right.$ and $\left.\mathrm{CH}_{3}\right)$ and constructed an extended chemical kinetic model to validate experimentally measured reaction intermediates and products. Through reaction flux analyses, they found that hydrogen abstraction from the $\beta$ carbon site (see R1 in Fig. 1), resulting into $\beta$-cyclopentanonyl ( $\beta$-CPOnyl) radical accounts major percentage of CPO consumption; whereas the formation of $\alpha$-cyclopentanonyl $(\alpha-$ CPOnyl) radical makes a minor contribution accounting for only $28 \%$ consumption under stoichiometric conditions at $850 \mathrm{~K}, 10 \mathrm{~atm}$. The incipient radicals have major effect in the overall oxidation kinetics of CPO because $\alpha$-CPOnyl is resonantly stabilized radical and is thus less reactive than $\beta$-CPOnyl radical. Therefore, the branching ratio of hydrogen abstraction reaction of CPO is of high importance for combustion modeling. Thion et al. ${ }^{20}$ further observed that $\mathrm{OH}$-initiated oxidation of $\mathrm{CPO}$ dominates between 850 and $1050 \mathrm{~K}$, and $\mathrm{H}$-abstraction by $\mathrm{H}$ atoms take the lead beyond $1050 \mathrm{~K}$. Finally, they realized a room for improvement of the kinetic model and demanded for additional measurements such as ignition delay times (IDTs) and laminar burning velocities to better understand the chemistry of CPO. Very recently, Zhang et al. ${ }^{19}$ investigated CPO oxidation by using a high-pressure shock tube and a rapid compression machine over a wide range of experimental condition $(T=794-1368 \mathrm{~K}, p=15$ and $30 \mathrm{bar}, \varphi$ $=0.5,1.0$ and 2.0). They measured ignition delay times (IDTs) and CO time-histories during CPO oxidation and also performed $a b$ initio/transition state theory calculations to derive the high-pressure limiting rate coefficients for the unimolecular decomposition of cyclopentanonyl peroxy radicals $\left(\mathrm{C}_{5} \mathrm{H}_{7} \mathrm{O}_{3}\right)$ forming cyclopentenone $\left(\mathrm{C}_{5} \mathrm{H}_{6} \mathrm{O}\right)$ and $\mathrm{HO}_{2}$. By incorporating the newly derived rate coefficients for $\mathrm{C}_{5} \mathrm{H}_{7} \mathrm{O}_{3}$ radicals, they developed a detailed kinetic model comprising of 444 species and 2269 reactions to describe the combustion behavior of CPO in their experiments. Overall, the kinetic model performed satisfactorily to reproduce their 
experimental data except that of the simulated IDTs at 1 atm which over-predicted experimentally measured IDTs. The authors noted the importance of the branching ratio of $\alpha$ and $\beta$-CPOnyl radicals in the overall oxidation kinetics of CPO. Similar to Thion et al. ${ }^{20}$, they arrived to a similar conclusion that the formation of $\beta$-CPOnyl radicals takes the major reaction flux during CPO oxidation. Their results showing the dominance of the $\beta$-CPOnyl radicals is probably not surprising considering the fact that the rate coefficients for reaction $(\mathrm{R} 1), k_{1}=k_{1 \alpha}$ $+k_{1 \beta}$, and the subsequent decomposition of the $\alpha$ - and $\beta$-CPOnyl radicals were adopted from Zhou et al. ${ }^{21}$. Zhou et al. ${ }^{21}$ used $a b$ initio/RRKM-ME calculations to show that reaction R1 predominantly occurs at the $\beta$-site with slightly decreasing importance at higher temperatures, e.g., $k_{1 \beta} / k_{1 \alpha}$ is 1.89 and 1.5 at $500 \mathrm{~K}$ and $1400 \mathrm{~K}$, respectively. Their predicted value of rate coefficient is faster by a factor of two than that of a single room-temperature measurement from Dagaut et al. ${ }^{27}$ who derived $k_{1}(298 \mathrm{~K})=(2.94 \pm 0.18) \times 10^{-12} \mathrm{~cm}^{3}$ molecule- ${ }^{1} \mathrm{~s}^{-1}$ using flash photolysis / resonance fluorescence technique. Theoretical rate coefficient of Thion et al. ${ }^{20}$ also over-predicts the experimental value by $\sim 30 \%$. The predictions of overall rate coefficients of $\mathrm{R} 1$ and the branching ratios from the two theoretical studies ${ }^{20-21}$ do not show good agreement. Both studies exhibit different temperature dependence of the rate coefficients. Therefore, there is a need to provide accurate rate coefficients for the hydrogen abstraction reaction to build a robust combustion model. 


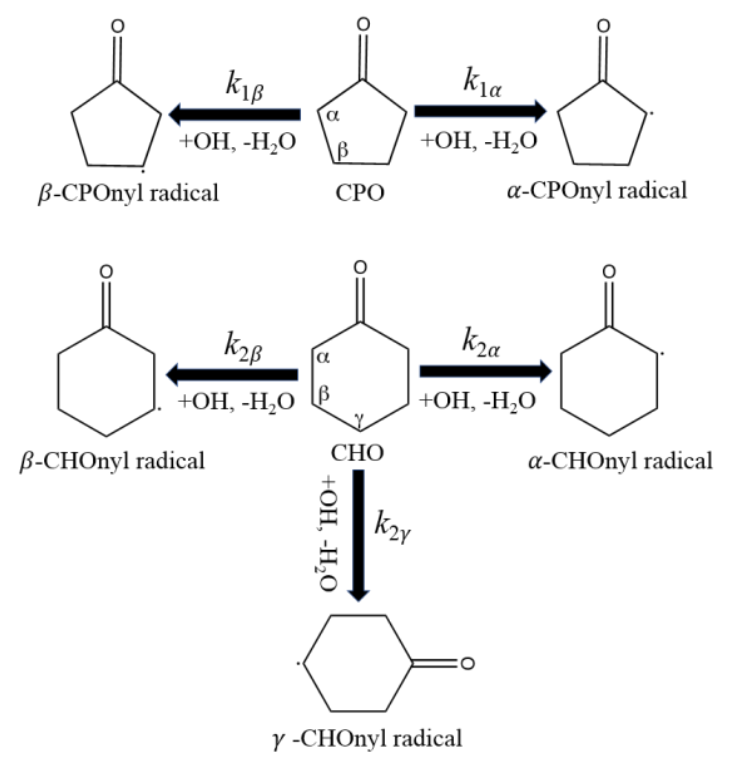

Figure 1: Hydrogen abstraction pathways for the reaction of cyclopentanone (CPO) and cyclohexanone $(\mathrm{CHO})$ with $\mathrm{OH}$ radicals.

As for cyclohexanone $(\mathrm{CHO})$, a recent paper by $\mathrm{He}$ et al. ${ }^{26}$ provides a brief literature review. Serinyel et al. ${ }^{25}$ studied the kinetics of $\mathrm{CHO}$ oxidation in a jet stirred reactor (JSR) over a wide range of experimental conditions $(T=530-1220 \mathrm{~K}, p=10 \mathrm{~atm}$ and $\varphi=0.5-4)$. They measured various species (reactants, intermediates and products) using gas chromatography and FTIR spectroscopy. They proposed a detailed kinetic model to reasonably describe their experimental results of $\mathrm{CHO}$ oxidation. However, their kinetic model did not accurately predict experimentally measured concentrations of all species. For this reason, the authors demanded for more experimental data to fully validate the proposed mechanism. Aiming for a better combustion model of cyclohexanone, He et al. ${ }^{26}$ measured ignition delay times of cyclohexanone behind reflected shock waves over $p=2.5-10$ atm, $T=1255-1646 \mathrm{~K}$ and $\varphi$ $=0.5-2.0$. The authors compared their measured values with the predictions from earlier kinetic model ${ }^{25}$ and found that the model over-predicted their measurements by $30-50 \%$. This motivated them to modify the earlier kinetic $\operatorname{model}^{25}$ by identifying key chemical reactions and updating their rate coefficients. Their modified kinetic model performed satisfactorily to reproduce their experimental data and previous JSR data. Moreover, the authors noted that 
hydrogen abstraction reactions of $\mathrm{CHO}$ play significant role, and the partitioning of $\alpha, \beta$ and $\gamma$ -CHOnyl radicals (see R2 in Fig. 1) shows different sensitivity towards CHO oxidation. For example, $\mathrm{H}$-abstraction from the $\alpha$-site of $\mathrm{CHO}$, resulting in $\alpha$-CHOnyl radical, was found to increase the global reactivity, whereas the formation of $\beta$-CHOnyl has the opposite effect. Contrary to the CPO oxidation model, the modified kinetic model from He et al. ${ }^{26}$ predicted the $\mathrm{H}$-abstraction reaction at the $\alpha$-site of $\mathrm{CHO}$ to be the dominant channel. Thion et al. ${ }^{28}$ recently also proposed an improved kinetic model for $\mathrm{CHO}$ oxidation by validating against their new JSR measurements to complement their earlier work. ${ }^{25}$ Their improved model favored the formation of $\beta$-CHOnyl radical as opposed to $\alpha$-CHOnyl contradicting the earlier models. However, this is in line with the kinetic model of CPO oxidation. They further performed G3//MP2/aug-cc-pVDZ and RRKM-ME calculations to obtain rate coefficients for important reactions, e.g., $\mathrm{H}$-abstraction reaction from $\mathrm{CHO}$ by $\mathrm{H}, \mathrm{OH}$ and $\mathrm{CH}_{3}$ radicals, isomerization and decomposition of $\alpha, \beta, \gamma$-CHOnyl radicals. Based on their new JSR experimental and computational results, they updated Serinyel et al.'s model ${ }^{25}$ and validated against the available data. However, we note here that the newly derived theoretical rate coefficients from this study are not validated against the experimentally measured kinetic data. The only available roomtemperature experimental value reported by Dagaut et al. ${ }^{27} k_{2}(298 \mathrm{~K})=(6.39 \pm 0.51) \times 10^{-12}$ $\mathrm{cm}^{3} \mathrm{~s}^{-1}$ is faster by $45 \%$ than that of theory. ${ }^{28}$ Therefore, there is a need for an experimental study of the rate coefficients of $\mathrm{CHO}+\mathrm{OH}$ reaction under combustion relevant conditions.

There are several motivations for the current work: i) from future fuels prospective, cyclic ketones are of significant interest to the combustion community; ii) the oxidation of cyclic ketones by $\mathrm{OH}$ radicals is one of the most important initiation step, and no direct measurements of rate coefficients of reaction R1 $\left(k_{1}=k_{1 \alpha}+k_{1 \beta}\right)$ and reaction R2 $\left(k_{2}=k_{2 \alpha}+k_{2 \beta}\right.$ $\left.+k_{2 \gamma}\right)$ are yet available at high temperatures; iii) As explained above, the oxidation kinetics of cyclic ketones is sensitive to the branching ratio of $\mathrm{R} 1$ and $\mathrm{R} 2$ which led to the disparity in 
terms of the performance of the available kinetic models; iii) large discrepancies exist among the theoretical predictions of the rate coefficients. Through this work, we aim to resolve the discrepancies in the literature by providing reliable data for the rate coefficient of R1 and R2 over a broad range of experimental conditions. To our knowledge, this is the first experimental investigation for the rate coefficients of $\mathrm{CPO}+\mathrm{OH}(\mathrm{R} 1)$ and $\mathrm{CHO}+\mathrm{OH}(\mathrm{R} 2)$ at high temperatures.

\section{Experimental Method}

The reaction kinetics of $\mathrm{OH}$ radicals with $\mathrm{C}_{5}-\mathrm{C}_{6}$ cyclic ketones was investigated over the temperature range of $900 \mathrm{~K}$ and $1300 \mathrm{~K}$, and pressures near 1.2 bar using a low-pressure shock tube (LPST) and UV laser diagnostic facility at KAUST. The experimental facility and diagnostic method have been detailed previously. ${ }^{29-30}$ The stainless steel shock tube has a $9 \mathrm{~m}$ long driven section and a variable length driver section, and both sections have an internal diameter of $14.2 \mathrm{~cm}$. In this study, a $3 \mathrm{~m}$ long driver section was used to achieve a test time of $\sim 1.5 \mathrm{~ms}$ behind reflected shock waves. The shock waves were generated by pressure bursting of polycarbonate diaphragms of $5 \mathrm{~mm}$ thickness and using helium as driver gas. The desired temperature and pressure behind reflected shock waves were achieved by tailoring the pressure differential across the diaphragm. A series of five piezoelectric transducers (PCB 113B26) over the last $1.5 \mathrm{~m}$ of the driven section were employed to measure the incident shock speed. The temperature and pressure behind reflected shock waves were calculated by using measured incident shock speed and thermodynamic data of the test gas mixture and by employing shockjump relations ${ }^{31}$ embedded in the Frosh code ${ }^{32}$.

Hydroxyl radicals were generated via fast thermal decomposition of a well-known clean $\mathrm{OH}$ precursor, tert-butyl hydroperoxide $(\mathrm{TBHP})^{33}$. The reaction kinetics of the title reaction was followed by monitoring $\mathrm{OH}$ radical decay near $307 \mathrm{~nm}$ via a narrow linewidth $\mathrm{cw}$ laser 
system comprised of an Nd:YAG $532 \mathrm{~nm}$ pump laser, a ring-dye visible laser and a frequency doubler. The UV light was tuned precisely to the center $(306.6868 \mathrm{~nm})$ of the well-characterized $\mathrm{R} 1(5)$ absorption line in the $(0,0)$ vibrational band of the $\mathrm{A}^{2} \Sigma^{+} \leftarrow \mathrm{X}^{2} \Pi$ electronic system of $\mathrm{OH}$ radical. For optical detection of $\mathrm{OH}$ radicals, the laser beam was guided through the crosssection of the shock tube via two quartz windows which are installed $2 \mathrm{~cm}$ away from the shock tube end wall. Two modified Thorlab PDA36-EC photodetectors (spectral range $305-1100 \mathrm{~nm}$ ) served to measure the laser intensity before and after the shock tube. The noise of the laser beam after common-mode-rejection was less than $0.1 \%$ of the signal. The laser intensity timeprofile was quantitatively converted into $\mathrm{OH}$ mole fraction $\left(\mathrm{X}_{\mathrm{OH}}\right)$ time-profile by using BeerLambert law.

The purity of used chemicals was: $99 \% \mathrm{CHO}$ and $\mathrm{CPO}$ (Sigma Aldrich; further purified through freeze-pump-thaw cycle), 70\% TBHP solution in water (Sigma Aldrich), helium (99.9\%) and argon (99.999\%) from Abdullah Hashim Gases. The desired gas mixtures were prepared manometrically in a 24 litre Teflon-coated stainless-steel vessel equipped with a magnetically driven stirrer. The mixtures were left for at least two hours to ensure homogeneity. Prior to mixture preparation, the mixing vessel was turbo-pumped down to $10^{-5}$ mbar. Partial pressures of cyclic ketones and TBHP were measured accurately using a 0-20 Torr MKS Baratron pressure gauge. For all measurements, an excess concentration of cyclic ketone (at least 10 times) as compared to that of $\mathrm{OH}$ radicals was used to ensure that $\mathrm{OH}$ radical decay will follow first-order kinetics.

\section{Results and Discussion}

Measurements were carried out behind reflected shock waves at $~ 1.2$ bar and varying temperatures between $900-1300 \mathrm{~K}$; experimental conditions are listed in Table 1. Two test 
gas mixtures of varying $\mathrm{CPO}$ and $\mathrm{CHO}$ concentrations were employed to ensure that the reaction under investigation is obeying pseudo first-order kinetics. Figure 2 illustrates a representative $\mathrm{OH}$ time-history measured at $1218 \mathrm{~K}$ and 1.13 bar for $\mathrm{CPO}+\mathrm{OH}(\mathrm{R} 1)$; the inset in Fig. 2 displays $\ln [\mathrm{OH}]$ vs time plot demonstrating that $\mathrm{OH}$ decay follows first-order kinetics. In such cases, the rate coefficients can be directly calculated from the pseudo first order plot. However, this methodology of extracting the rate coefficients can't be applied at lower temperatures $(<950 \mathrm{~K})$. Below $950 \mathrm{~K}$, the decomposition of TBHP is slow, and the OH rise time becomes of the order of the decay time - (see $\mathrm{CPO}+\mathrm{OH}$ data measured at $902 \mathrm{~K}$ and 1.26 bar presented in the Supporting Information as an example). Therefore, detailed kinetic model is critically important to accurately determine the rate coefficients for reactions R1 and R2 to account for the effect of $\mathrm{OH}$ build up kinetics and $\mathrm{OH}$ loss by unwanted reactions e.g. $\mathrm{CH}_{3}+$ OH. For the detailed model, we added TBHP sub-mechanism of Pang et al. ${ }^{34}$ to the existing kinetic models for CPO and CHO developed by Thion et al. ${ }^{20}$ and Serinyel et al. ${ }^{25}$, respectively. We iteratively varied the rate coefficient of the target reaction to obtain the best match between the experimental and simulated $\mathrm{OH}$ profiles. We employed Chemkin-Pro ${ }^{35}$ software to simulate $\mathrm{OH}$ profiles using zero-dimensional batch reactor and constant $U, V$ constraints. The red line in Fig. 2 demonstrates an example of such simulation result, and also shown is the perturbation of $\pm 50 \%$ from the best-fit value $\left(k_{1}=2.39 \times 10^{-11} \mathrm{~cm}^{3}\right.$ molecule $\mathrm{s}^{-1} \mathrm{~s}^{-1}$ at $\left.1218 \mathrm{~K}, 1.13 \mathrm{bar}\right)-$ more examples are provided in the Supporting Information. The perturbation analysis shows strong sensitivity of $k_{1}$ towards $\mathrm{OH}$ decay. Further hydroxyl radical sensitivity analyses show negligible contribution from secondary chemistries on the measured $\mathrm{OH}$ time-history (see Fig. 3). Also, we found negligible influence of the branching ratio on our determined overall rate coefficients. Accounting for uncertainties in the temperature $( \pm 0.7 \%)$ of reflected shock wave, fitting the measured $\mathrm{OH}$ profile $( \pm 6 \%)$, $\mathrm{OH}$ absorption coefficient $( \pm 3 \%)$, test gas composition 
$( \pm 5 \%)$, and locating time zero $( \pm 0.5 \mu \mathrm{s})$ gives an overall uncertainty $(2 \sigma)$ of $\pm 20 \%$ in our measured values of the rate coefficients.

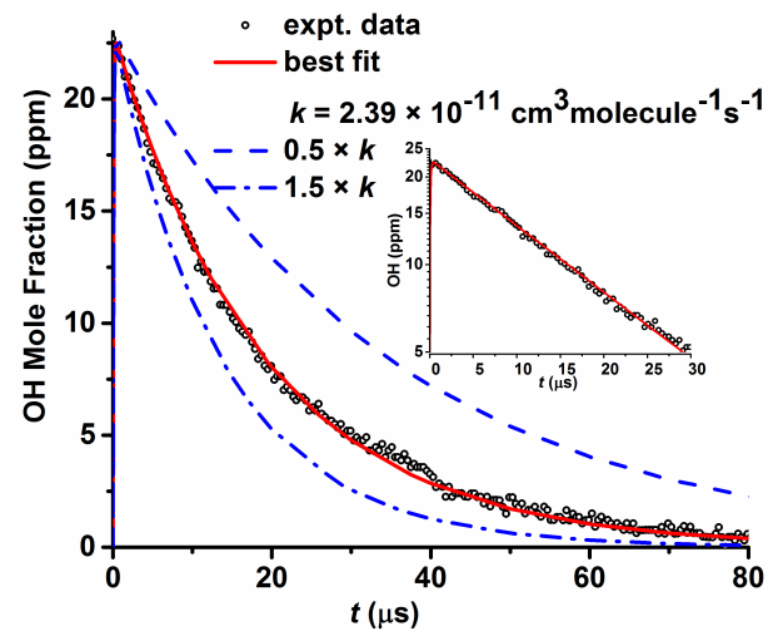

Figure 2. A representative $\mathrm{OH}$ time-history plot for $\mathrm{CPO}+\mathrm{OH} \rightarrow$ products $(\mathrm{R} 1)$ at $1218 \mathrm{~K}$ and

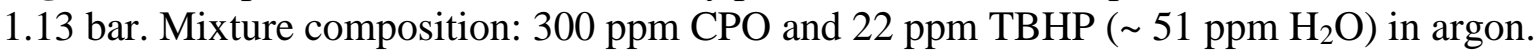

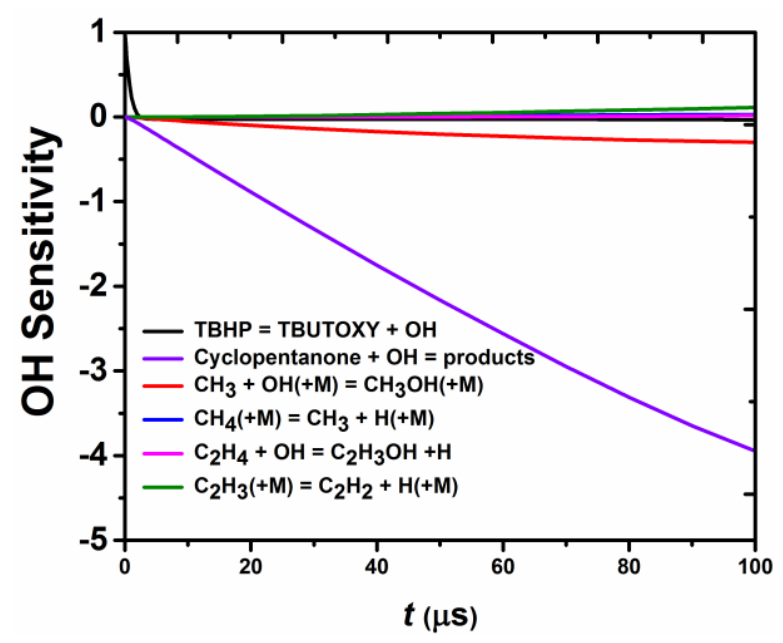

Figure 3. Hydroxyl radical sensitivity analysis for $\mathrm{CPO}+\mathrm{OH} \rightarrow$ products (R1) carried out $1218 \mathrm{~K}$ and 1.13 bar using the detailed kinetic model described in the text. The most sensitive reactions are shown in the figure legend. The $\mathrm{OH}$ sensitivity is defined as $S_{\mathrm{OH}}=\left(\partial X_{\mathrm{OH}} / \partial k_{\mathrm{i}}\right) \times\left(k_{\mathrm{i}}\right.$ $\left./ X_{\mathrm{OH}}\right)$, where the $X_{\mathrm{OH}}$ is local $\mathrm{OH}$ mole fraction and $k_{\mathrm{i}}$ is the rate constant of the $i^{\text {th }}$ reaction.

Table 1 compiles the overall rate coefficients for $k_{1}$ and $k_{2}$ from current measurements. Arrhenius plots of these rate coefficients are shown in Fig. 4 along with the available literature data. As stated earlier, there are no previous experimental data at high temperatures to compare 
with our data. The existing theoretical studies ${ }^{20-21,28}$ do not accurately reproduce our experimentally measured rate coefficients, as shown in Fig. 4.

Table 1: Measured rate coefficients for the reactions of $\mathrm{OH}$ radical with $\mathrm{CPO}$ and $\mathrm{CHO}$.

\begin{tabular}{|c|c|c|}
\hline$P_{5}$ & $T_{5}$ & $k / 10^{-11}$ \\
\hline bar & $\bar{K}$ & $\mathrm{~cm}^{3}$ molecule ${ }^{-1} \mathrm{~s}^{-1}$ \\
\hline \multicolumn{3}{|c|}{$\begin{array}{l}\text { Mixture 1: } 400 \text { ppm cyclopentanone, } 20 \\
\text { ppm TBHP ( } 47 \mathrm{ppm} \text { water }) \text { in argon }\end{array}$} \\
\hline 1.14 & 982 & 1.38 \\
\hline 1.32 & 983 & 1.3 \\
\hline 1.62 & 983 & 1.33 \\
\hline 1.32 & 1152 & 1.93 \\
\hline 1.12 & 1236 & 2.33 \\
\hline \multicolumn{3}{|c|}{$\begin{array}{l}\text { Mixture 2: } 300 \text { ppm cyclopentanone, } 25 \\
\text { ppm TBHP( } \sim 58 \text { ppm water }) \text { in argon }\end{array}$} \\
\hline 1.26 & 902 & 1.33 \\
\hline 1.39 & 924 & 1.38 \\
\hline 1.58 & 1085 & 1.5 \\
\hline 1.06 & 1128 & 1.66 \\
\hline 1.13 & 1218 & 2.39 \\
\hline 1.11 & 1222 & 2.44 \\
\hline 1.41 & 1225 & 2.16 \\
\hline 1.54 & 1297 & 2.56 \\
\hline \multicolumn{3}{|c|}{$\begin{array}{c}\text { Mixture 3: } 300 \text { ppm cyclohexanone, } 20 \text { ppm } \\
\text { TBHP ( } 47 \text { ppm water)in argon } \\
\end{array}$} \\
\hline 1.12 & 1023 & 2.16 \\
\hline 1.27 & 1033 & 2.28 \\
\hline 1.14 & 1189 & 3.16 \\
\hline \multicolumn{3}{|c|}{$\begin{array}{c}\text { Mixture 4: } 300 \mathrm{ppm} \text { cyclohexanone, } 40 \mathrm{ppm} \\
\text { TBHP( } 93 \mathrm{ppm} \text { water }) \text { in argon }\end{array}$} \\
\hline 1.29 & 935 & 1.83 \\
\hline 1.22 & 949 & 1.99 \\
\hline 1.2 & 1107 & 2.66 \\
\hline 1.11 & 1219 & 3.16 \\
\hline 1.08 & 1251 & 3.57 \\
\hline 1.15 & 1331 & 3.82 \\
\hline \multicolumn{3}{|c|}{$\begin{array}{l}\text { Mixture 5: } 399.5 \mathrm{ppm} \text { cyclohexanone, } 25 \\
\text { ppm TBHP( } \sim 60 \mathrm{ppm} \text { water }) \text { in argon }\end{array}$} \\
\hline 1.12 & 890 & 1.74 \\
\hline 0.90 & 1112 & 2.66 \\
\hline
\end{tabular}




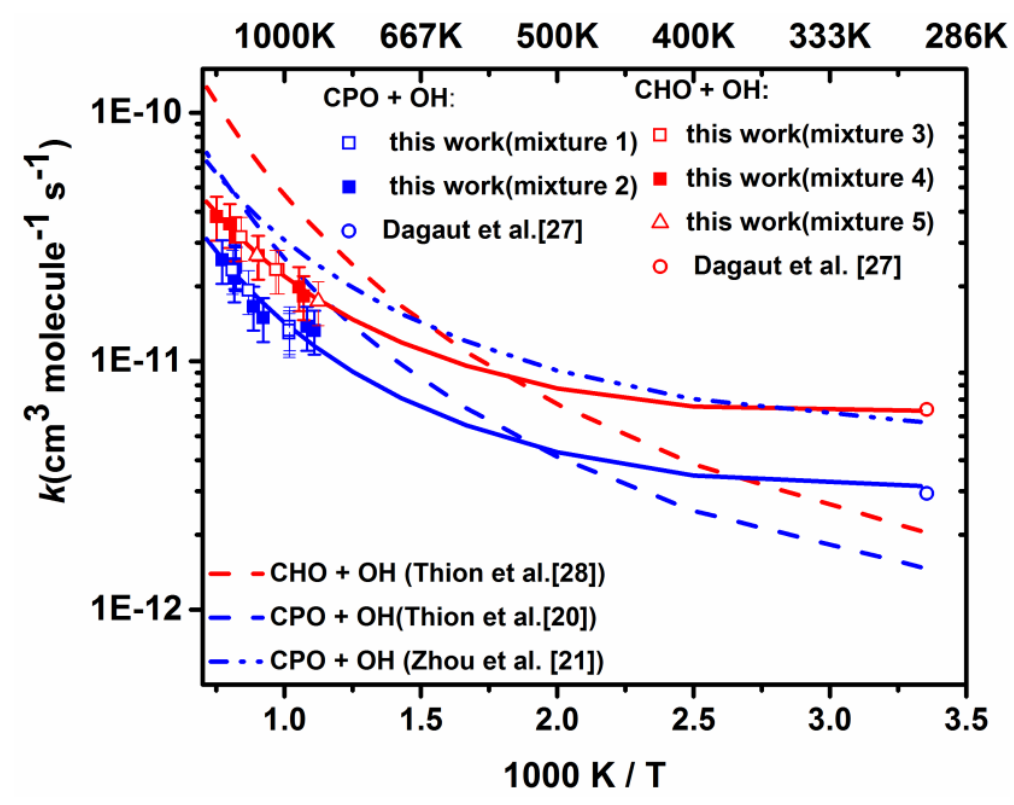

Figure 4. Arrhenius plots for the total rate coefficients of $\mathrm{CPO}+\mathrm{OH}(\mathrm{R} 1)$ and $\mathrm{CHO}+\mathrm{OH}$ (R2); also shown are available literature data. Solid lines represent the recommended 3parameter Arrhenius expressions, given by Eqs. (1) and (2) of this work. Dash and dash-dotdot lines represent literature theoretical predictions.

For $\mathrm{CPO}+\mathrm{OH}(\mathrm{R} 1)$ reaction, both theoretical works ${ }^{20-21}$ exhibit very different reactivity behavior in terms of their temperature dependence. As can be seen in Figure 4 (blue dash-dotdot line), the predicted rate coefficients from Zhou et al. ${ }^{21}$ run almost parallel to the experimental data while over-predicting the experimental rate coefficients by a factor of $\sim 2$. This may suggest that the calculated energy barriers for R1 are nearly accurate, but the preexponential factor seems to have been over-estimated. The theoretical rate coefficients from Thion et al. ${ }^{20}$ show stronger $T$-dependance while under-predicting the single room temperature value of Dagaut et al. ${ }^{27}$ but over-predicting our high-temperature data by roughly a factor of two. This may indicate that barrier heights predicted by Thion et al. ${ }^{20}$ at G3//MP2/aug-ccpVDZ level of theory are somewhat too high. At this level of theory, their predictions of all the transition states (TS) responsible for the hydrogen abstraction reactions lie higher in energy relative to the reactants $(\mathrm{CPO}+\mathrm{OH})$. On the other hand, Zhou et al. ${ }^{21}$ predicted negative barriers for some abstraction reactions at G4 and $\operatorname{CCSD}(\mathrm{T}) / \mathrm{CBS}$ levels of theory, e.g., TS abstracting 
equatorial hydrogen atoms at the $\alpha$-sites $\left(E_{0}=-0.3 \mathrm{kcal} / \mathrm{mol}\right)$. Although the diffrence in the energy barriers is small $(<1 \mathrm{kcal} / \mathrm{mol})$ and remains within the uncertainty of the electronic energy calculations, it can have a large effect in the quality of the predicted rate coefficiens, as observed in these chemical systems.

For $\mathrm{CHO}+\mathrm{OH}(\mathrm{R} 2)$ reaction, Thion et al. ${ }^{28}$ theoretical rate coefficients over-predicated our experimental data by at least a factor of 2.5 , but they under-predicted room-temperature data of Dagaut et al. ${ }^{27}$ by a factor of 1.4 . This also suggests an overestimation of the barrier heights for the abstraction pathways of R2. Therefore, the existing theoretical models need to be further tuned by anchoring with these new experimental data from this work, and update accordingly in the kinetic models. As expected, cyclohexanone (CHO) shows larger overall reactivity towards $\mathrm{OH}$ radicals as opposed to cyclopentanone $(\mathrm{CPO})$ due to the presence of two additional hydrogen atoms at the $\gamma$-sites. Combining the high-temperature data from this work with the single room-temperature measurement from Dagaut et al. ${ }^{27}$, the following threeparameter Arrhenius expressions are recommended for $k_{1}$ and $k_{2}$ over a wide range of temperatures:

$$
\begin{array}{lll}
k_{1}(\mathrm{CPO}+\mathrm{OH})=1.07 \times 10^{-13}\left(\frac{T}{300 K}\right)^{3.2} \exp \left(1005.7 \frac{K}{T}\right) & 298-1297 \mathrm{~K} & \text { Eq. }(1) \\
k_{2}(\mathrm{CHO}+\mathrm{OH})=3.12 \times 10^{-13}\left(\frac{T}{300 K}\right)^{2.78} \exp \left(897.5 \frac{K}{T}\right) & 298-1331 \mathrm{~K} & \text { Eq. }(2)
\end{array}
$$

As shown in Fig. 4, Eqs. (1) and (2) reproduce the experimental data remarkably well over the entire temperature range with an average absolute deviation of $7 \%$ and $3 \%$ for $k_{1}$ and $k_{2}$, respectively. In the intermediate $T$-range, where experimental data are not yet available, Eqs. (1) and (2) are still expected to reliably estimate the rate coefficients for two reasons: i) the tunneling is not severe for these reactions, e.g., tunneling correction factors are 1.8 and 1.2 at 500 and $1000 \mathrm{~K}$, respectively ${ }^{21}$; ii) $\mathrm{OH}$ addition to the carbonyl group of cyclic ketones, leading to bimolecular products, which typically shows a complex kinetic behavior, is insignificant. We 
arrive to this conclusion by taking an analogy to dimethyl ketone $+\mathrm{OH}$ reaction where the contribution of addition channel is less than $1 \%$ over $500-2000 \mathrm{~K} .^{36}$

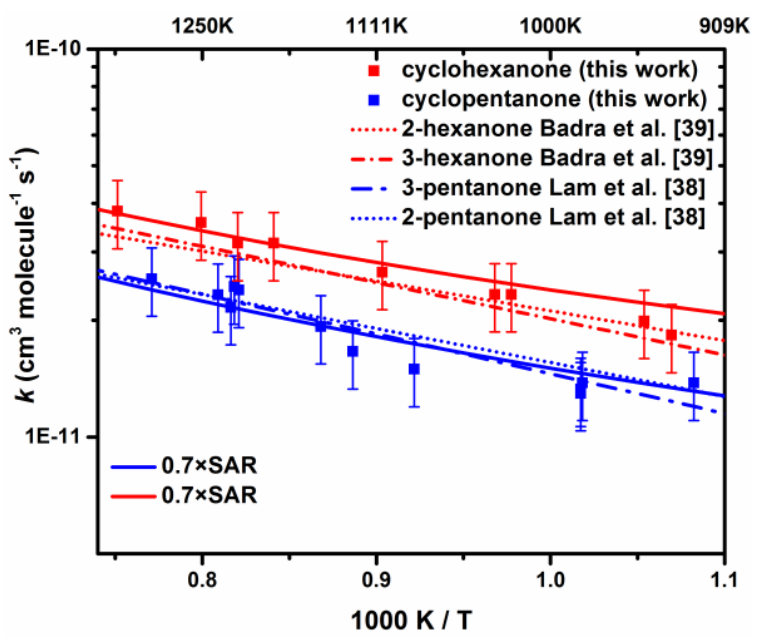

Figure 5. Comparison of the rate coefficients of cyclic ketones $+\mathrm{OH}$ with normal-chain ketones $+\mathrm{OH}$ counterparts. Also shown are predictions of structure activity relationship (SAR) multiplied by 0.7 .

Figure 5 compares the reactivity of $\mathrm{OH}$ radicals with the cyclic ketones and their corresponding normal-chain ketone counterparts. Interestingly, within the uncertainties of the experiments, these cyclic ketones exhibit similar reactivity as their normal-chain ketone counterpart for the temperature range of $900-1300 \mathrm{~K}$. This may just be fortuitous as we expect a little variation in the barrier heights for the hydrogen abstraction from different chemical environments of these ketones by $\mathrm{OH}$ radicals. For instance, the transition state for the hydrogen abstraction of $\mathrm{CH}_{3}-\mathrm{C}(\mathrm{O})-\mathrm{CH}_{3}$ via complex formation lies about $2.4 \mathrm{kcal} / \mathrm{mol}$ above the reactant energy, whereas these are about 2.1 and $0.5 \mathrm{kcal} / \mathrm{mol}$ for $\mathrm{CH}_{3}$-sites of $\mathrm{CH}_{3}-\mathrm{C}(\mathrm{O})-\mathrm{CH}_{2}-\mathrm{CH}_{3}$ adjacent to and far from the carbonyl group, respectively, and the $-\mathrm{CH}_{2}$ site lies below the reactant by $-0.1 \mathrm{kcal} / \mathrm{mol}$. These barrier heights were calculated at G3 level of theory by Zhou et al. ${ }^{36}$. We caution for this sort of reaction analogy beyond $900-1300 \mathrm{~K}$ as these ketones of same carbon number do have different $\mathrm{C}-\mathrm{H}$ chemical sites. As a result, they display variations in the reactivity with $\mathrm{OH}$ radicals as manifested by the difference in the temperature dependence 
of the rate coefficients from different chemical environments. We employed the structureactivity relationship (SAR) ${ }^{37}$ to estimate the rate coefficients for R1 and R2, and found that SAR over-estimated our experimental data. Similar reports were made by Lam et al. ${ }^{38}$ for $\mathrm{OH}$ reactions with 2-butanone, 2-pentanone and 3-pentanone and by Badra et al. ${ }^{39}$ for 2- and 3hexanones. SAR predictions are multiplied by a factor of 0.7 to obtain a good agreement with the experimental data. We note here that similar value for the multiplicative factor $(0.75)$ were used by earlier studies ${ }^{38-39}$ for ketones $+\mathrm{OH}$ reaction systems.

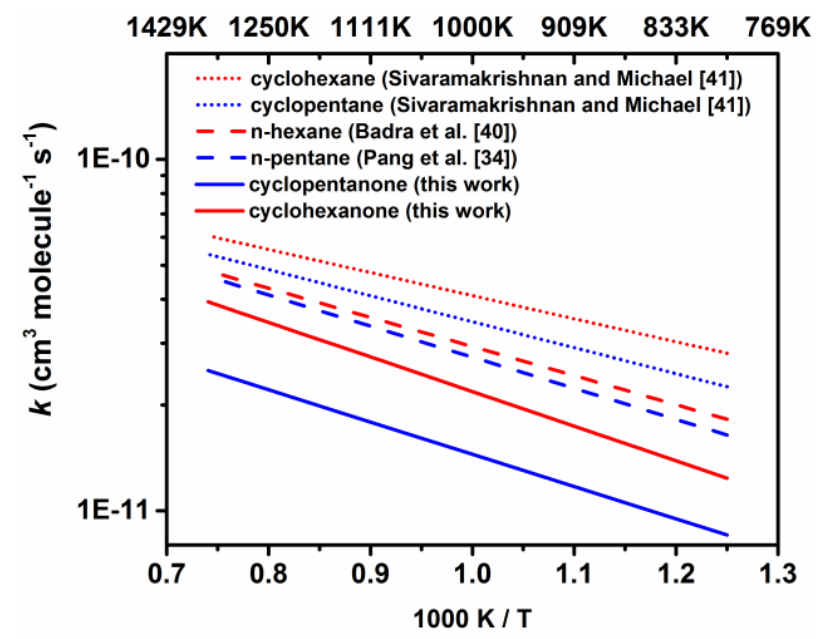

Figure 6. Reactivity trends of $\mathrm{C}_{5}-\mathrm{C}_{6}$ cyclic ketones and corresponding hydrocarbons with $\mathrm{OH}$ radicals.

In Fig. 6, we further compare the $\mathrm{OH}$ reactivity of cyclic ketones with that of $\mathrm{C}_{5}-\mathrm{C}_{6}$ cyclic and acyclic hydrocarbons from earlier reports of Pang et al. ${ }^{34}$, Badra et al. ${ }^{40}$ and Sivaramakrishnan and Michael ${ }^{41}$. As can be seen, the reactivity trend is found to be in the order $k($ cyclicketone $+\mathrm{OH})<k($ alkane $+\mathrm{OH})<k($ cyclicalkanes $+\mathrm{OH})$ for a given length of carbon chain. Here, a couple of things may be noted: i) not surprisingly the number of secondary abstractable hydrogen atoms matter, e.g., $k($ pentane $+\mathrm{OH})<k($ hexane $+\mathrm{OH})$, ii) type of chemical environments also play a crucial role, e.g., $k$ (cyclohexanone $+\mathrm{OH})<k($ cyclopentane $+\mathrm{OH})$ despite of the fact that both molecules have 10 secondary hydrogen atoms, iii) total 
number of abstractable hydrogen atoms matter, e.g., $k($ cyclopentanone $+\mathrm{OH})<k$ (pentane + $\mathrm{OH})$. Here, it is particularly interesting to note the slower reactivity of cyclohexanone as opposed to cyclopentane. In fact, one would expect the opposite reactivity trend since both molecules offer 10 secondary hydrogen atoms for abstraction, and the hydrogen abstraction reaction of cyclohexanone by $\mathrm{OH}$ radicals is expected to largely occur at $\alpha \mathrm{C}-\mathrm{H}$ sites because these are significantly weaker than $\beta$ or $\gamma \mathrm{C}-\mathrm{H}$ sites as well as the $\mathrm{C}-\mathrm{H}$ sites of cyclopentane (see Fig. 7). Unexpectedly, the hydrogen abstraction reaction of $\mathrm{OH}$ radicals from the $\alpha$-sites of cyclic ketones are found to undergo slower reaction than that of $\beta$-sites, which is in contrary to the trend observed for the hydrogen abstraction reactions of cyclic ketones by $\mathrm{HO}_{2}, \mathrm{CH}_{3}, \mathrm{H}$ and $\mathrm{O}$ radicals ${ }^{20-21}$. This observation clearly hints towards the mechanistic differences for these reactions. Generally, the hydrogen abstraction reaction of $\mathrm{OH}$ radicals with oxygenates undergoes via addition-elimination mechanism forming complexes both at the entrance and exit channels which is not the case for (a) cyclic hydrocarbons $+\mathrm{OH}$ reactions. Here, the reactions of cyclic ketones $+\mathrm{OH}$ are not the exception either in terms of complex forming reactions as shown by recent theoretical works ${ }^{20-21}$. These works have shown that $\mathrm{H}$-abstraction at the close proximity of carbonyl group of cyclic ketones by $\mathrm{OH}$ radicals occurs via complex forming mechanism in an overall exothermic process, and in particular, the transition state responsible for the abstraction of $\alpha$-equatorial is relatively stable due to hydrogen bonding forming a sixmember ring structure. This cyclization in the transition state lowers the energy barrier and also the entropy. Here, the entropy wins the competition making $\beta$-channels react faster than $\alpha$ channel. Thion et al. ${ }^{20}$ listed the entropy changes $\left(\Delta S^{\circ}\right)$ for $\alpha$ - and $\beta$-channel of R1, in units of cal $\mathrm{K}^{-1} \mathrm{~mol}^{-1}$, to be 1.1 and 7.1 at $1000 \mathrm{~K}$, respectively. This effect is not pronounced for other reactions, e.g., cyclic ketones $+\mathrm{HO}_{2}{ }^{20-21}$, and for these reactions, the relative barrier heights largely affect their rate coefficients. As for the cyclic alkanes $+\mathrm{OH}$ reactions, only direct 
abstraction pathways are feasible and their corresponding barrier heights display pronounced effect towards their reactivity.<smiles>C=CC(CC)(CC)C(C)(C)C(=O)C1CC2CCC1C2</smiles>

(CPO)<smiles>O=C1CCCCC1</smiles>

Cyclohexanone

$(\mathrm{CHO})$

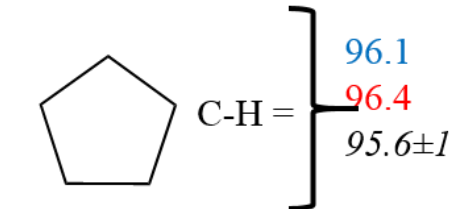

Cyclopentane

(CP)

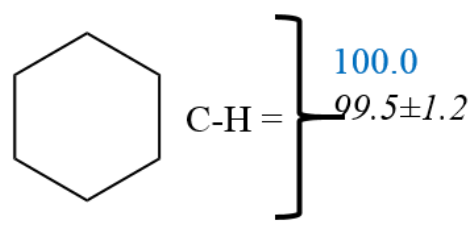

Cyclohexane

$(\mathrm{CH})$

Figure 7. Comparison of the bond dissociation energies (BDEs in $\mathrm{kcal} / \mathrm{mol}$ ) for various $\mathrm{C}-\mathrm{H}$ sites. For CPO and CP, the BDEs at CBS-QB3 (blue) and G3B3 (red) at $0 \mathrm{~K}$ from Thion et al. $^{20}$, G4 (black) at $298.15 \mathrm{~K}$ from Zhou et al. ${ }^{21}$, experimental (italic) from Tian et al. ${ }^{42}$. BDEs for $\mathrm{CHO}$ are from Zaras et al. ${ }^{24}$; BDEs for cyclohexane $(\mathrm{CH})$ at $\mathrm{G} 3$ (blue) and experimental (italic) are from Tian et al. ${ }^{42}$.

As outlined above, the oxidation kinetics of these cyclic ketones are very sensitive to the braching ratios of reactions $\mathrm{R} 1$ and $\mathrm{R} 2$. Therefore, we make a naïve attempt to discern the site-specific rate coefficients for R1 and R2. As seen in Fig. 7, the bond dissociation energies at the $\alpha$ and $\beta$ sites of $\mathrm{CPO}$ and $\mathrm{CHO}$ are comparable. Therefore, their reactivity towards $\mathrm{OH}$ at the corresponding sites can be assumed to be equal after ring strain factors are incorporated. For these reasons, we write: $k_{1}=k_{1 \alpha}+k_{1 \beta} \approx F\left(k_{\alpha}+k_{\beta}\right)$ and $k_{2}=k_{2 \alpha}+k_{2 \beta}+k_{2 \gamma} \approx\left(k_{\alpha}+k_{\beta}+k_{\gamma}\right)$; where we use $F \sim 1$ for ring strain correction from the experimental data of Sivaramakrishnan and Michael ${ }^{41}$. Although Zhou et al. ${ }^{21}$ overall theoretical rate coefficients over-predicted experimental data by roughly a factor of two, the ratio $k_{\beta} / k_{\alpha} \approx 1.65$ over $800-1400 \mathrm{~K}$ is 
assumed to be valid. With $k_{\beta} / k_{\alpha} \approx 1.65$, using Eq. (1), we derive the following three parameter Arrhenius expression for $k_{\alpha}$ (in units of $\mathrm{cm}^{3}$ molecule $\mathrm{s}^{-1}$ ):

$k_{a}(T)=4.38 \times 10^{-14}\left(\frac{T}{300 K}\right)^{3.17} \exp \left(978.4 \frac{K}{T}\right) \quad 800-1400 \mathrm{~K} \quad$ Eq. (3)

Thereafter, with the known values of $k_{\alpha}$ and $k_{\beta}, k_{\gamma}$ can be deduced with the help of Eq. (2) which may be expressed by the following Arrhenius expression (in units of $\mathrm{cm}^{3}$ molecule $\mathrm{s}^{-1}$ ):

$k_{\gamma}(T)=1.23 \times 10^{-12}\left(\frac{T}{300 K}\right)^{1.45} \exp \left(119.5 \frac{K}{T}\right) \quad 800-1400 \mathrm{~K} \quad$ Eq. (4)

The derived rate coefficient for $k_{\gamma}$ agrees reasonably well, with an average deviation of $+17 \%$, with the value from Sivaramakrishnan and Michael $^{41}$ for cyclohexane $+\mathrm{OH}$ reaction. This slightly increased reactivity of $k_{\gamma}$ as compared to that of cyclohexane $+\mathrm{OH}$ reaction may be attributed to the slightly lower ( 1 kcal/mol) C-H bond dissociation energy (see Fig. 7).

\section{Conclusions}

Cyclic ketones have caught significant attention of the combustion community because they can be derived from biomass and display desirable combustion characteristics for application in future advance combustion engines. We have, for the first time, investigated hydrogen abstraction reactions of $\mathrm{C}_{5}-\mathrm{C}_{6}$ cyclic ketones by $\mathrm{OH}$ radicals under combustion relevant conditions. We employed shock tube/laser diagnostic technique to follow the kinetics of $\mathrm{OH}$ radical reactions with $\mathrm{C}_{5}-\mathrm{C}_{6}$ cyclic ketones over a wide range of temperatures $(T=900-1300$ $\mathrm{K})$. Under the current experimental conditions, cyclic ketones $+\mathrm{OH}$ are found to exhibit similar reactivity as that of similar carbon length acyclic ketones $+\mathrm{OH}$ reactions. Earlier theoretical studies are unable to accurately predict the measured rate coefficients. However, by incorporating a correction factor of 0.7 , SAR captured the experimentally measured temperature dependence of the rate coefficients for $\mathrm{R} 1$ and $\mathrm{R} 2$ reasonably well. These new data 
would prove beneficial to significantly improve the global performance of the oxidation kinetic models of cyclic ketones.

\section{Associated Content}

Supporting Information. The supporting information is available free of charge on the ACS Publication website at DOI:

Additional $\mathrm{OH}$-times histories and simulation results using detailed kinetic models

\section{Acknowledgements}

Research reported in this publication was funded by the Office of Sponsored Research at King Abdullah University of Science and Technology (KAUST).

\section{References}

1. OECD, Oil 2018. OECD Publishing, Paris, 2018; p 137.

2. Kalghatgi, G. T. The Outlook for Fuels for Internal Combustion Engines. Int. J. Engine. Res. 2014, 15, 383-398.

3. Kalghatgi, G. T. Developments in Internal Combustion Engines and Implications for Combustion Science and Future Transport Fuels. Proc. Combust. Inst. 2015, 35, 101-115.

4. Kalghatgi, G. T. Fuel/Engine Interactions. SAE international, 2014, ISBN 978-0-7680$6458-2$. 
5. Sarathy, S. M.; Kukkadapu, G.; Mehl, M.; Javed, T.; Ahmed, A.; Naser, N.; Tekawade, A.; Kosiba, G.; AlAbbad, M.; Singh, E. et al. A. Compositional Effects on the Ignition of FACE Gasolines. Combust. Flame. 2016, 169, 171-193.

6. Sarathy, S. M.; Kukkadapu, G.; Mehl, M.; Wang, W.; Javed, T.; Park, S.; Oehlschlaeger, M. A.; Farooq, A.; Pitz, W. J.; Sung, C.-J. Ignition of Alkane-Rich FACE Gasoline Fuels and Their Surrogate Mixtures. Proc. Combust. Inst. 2015, 35, 249-257.

7. Farrell, J.; John Holladay, Wagner R. Fuel Blendstocks with the Potential to Optimize Future Gasoline Engine Performance: Identification of Five Chemical Families for Detailed Evaluation. Technical Report DOE/GO-102018-4970. US Department of Energy, Washington, DC, 2018.

8. Miles, P. Efficiency Merit Function for Spark Ignition Engines: Revisions and Improvements Based on FY16-17 Research. U.S. Department of Energy, Washington, DC, 2018.

9. Strobel, G. A.; Knighton, W.B.; Kluck, K.; Ren, Y.; Livinghouse, T.; Griffin, M.; Spakowicz, D.; Sears, J. The Production of Myco-Diesel Hydrocarbons and their Derivatives by the Endophytic Fungus Gliocladium Roseum (NRRL 50072). Microbiology 2010, 156, 3830-3833.

10. Luque, R.; Lin, C..; Wilson, K.; Clark, J. Handbook of Biofuels Production: Processes and Technologies. $2^{\text {nd }}$ edition,Woodhead Publishing, 2016, ISBN: 9780081004555.

11. Demirbas, A. The Influence of Temperature on the Yields of Compounds Existing in Bio-Oils Obtained From Biomass Samples Via Pyrolysis. Fuel. Process. Technol. 2007, 88, 591-597.

12. Hronec, M.; Fulajtarová, K. Selective Transformation of Furfural to Cyclopentanone. Catal. Commun. 2012, 24, 100-104.

13. Engine Fuel Co-optimization Database[online] 
https://fuelsdb.nrel.gov/fmi/webd/FuelEngineCoOptimization (accessed April 5, 2019).

14. Yang, Y.; Dec, J. Bio-Ketones: Autoignition Characteristics and Their Potential as Fuels for HCCI Engines. SAE Int. J. Fuels Lubr. 2013, 6, 713-728.

15. Boot, M.; Frijters, P.; Luijten, C.; Somers, B.; Baert, R.; Donkerbroek, A.; KleinDouwel, R. J. H.; Dam, N. Cyclic Oxygenates: A New Class of Second-Generation Biofuels for Diesel Engines. Energ. Fuel. 2009, 23, 1808-1817.

16. Klein-Douwel, R. J. H.; Donkerbroek, A. J.; Vliet, A. P.; Boot, M. D.; Somers, L. M. T.; Baert, R. S. G.; Dama, N. J.; Meulen, J. J. Soot and Chemiluminescence in Diesel Combustion of Bio-derived, Oxygenated and Reference Fuels. Proc. Combust. Inst. 2009, 32, $2817-2825$.

17. Yang, J.; Li, N.; Li, G.; Wang, W.; Wang, A.; Wang, X.; Cong, Y.; Zhang, T. Synthesis of Renewable High-density Fuels Using Cyclopentanone Derived from Lignocellulose. Chem. Commun. (Camb.) 2014, 50, 2572-4.

18. Wang, W.; Li, N.; Li, G.; Li, S.; Wang, W.; Wang, A.; Cong, Y.; Wang, X.; Zhang, T. Synthesis of Renewable High-Density Fuel with Cyclopentanone Derived from Hemicellulose. ACS Sustain. Chem. Eng. 2017, 5, 1812-1817.

19. Zhang, K.; Lokachari. N.; Ninnemann, E.; Khanniche, S.; Green ,W. H.; Curran, H. J.; Vasu S. S.; Pitz W. J. An Experimental, Theoretical, and Modeling Study of the Ignition Behavior of Cyclopentanone. Proc. Combust. Inst. 2019, 37, 657-665.

20. Thion, S.; Togbe, C.; Dayma, G.; Serinyel, Z.; Dagaut, P. Experimental and Detailed Kinetic Modeling Study of Cyclopentanone Oxidation in a Jet-Stirred Reactor at 1 and 10 atm. Energ. Fuel. 2016, 31, 2144-2155.

21. Zhou, C. W.; Simmie, J. M.; Pitz, W. J.; Curran, H. J. Toward the Development of a Fundamentally Based Chemical Model for Cyclopentanone: High-Pressure-Limit Rate 
Constants for H Atom Abstraction and Fuel Radical Decomposition. J. Phys. Chem. A. 2016, 120, 7037-7044.

22. Zaras, A. M.; Thion, S.; Dagaut, P. Computational Kinetic Study for the Unimolecular Decomposition of Cyclopentanone. Int. J. Chem. Kinet. 2015, 47, 439-446.

23. Giri, B. R., AlAbbad, M., Barker, J. R.; Farooq, A. High Temperature Unimolecular Decomposition of Cyclopentanone. Proc. Combust. Inst. 2018, 37, 267-273.

24. Zaras, A. M.; Dagaut, P.; Serinyel, Z. Computational Kinetic Study for the Unimolecular Decomposition Pathways of Cyclohexanone. J. Phys. Chem. A. 2015, 119, 71387144.

25. Serinyel, Z.; Togbe, C.; Zaras, A.; Dayma, G.; Dagaut, P. Kinetics of Oxidation of Cyclohexanone In a Jet-Stirred Reactor: Experimental and Modeling. Proc. Combust. Inst. 2015, 35, 507-514.

26. He, J. N.; Gou, Y.; Lu, P. F.; Zhang, C. H.; Li, P.; Li, X. Shock Tube Measurements and Kinetic Modeling Study on Autoignition Characteristics of Cyclohexanone. Combust. Flame. 2018, 192, 358-368.

27. Dagaut, P.; Wallington, T. J.; Liu, R.; Kurylo, M. J. A Kinetics Investigation of the GasPhase Reactions of $\mathrm{OH}$ Radicals with Cyclic Ketones and Diones: Mechanistic Insights. $J$. Phys. Chem. 1988, 92, 4375-4377.

28. Thion, S.; Serinyel, Z.; Dayma, G.; Dagaut, P. More Insight Into Cyclohexanone Oxidation: Jet-stirred Reactor Experiments and Kinetic Modeling. Fuel 2018, 220, 908-915. 29. Badra, J.; Khaled, F.; Giri, B. R.; Farooq, A. A Shock Tube Study of the Branching Ratios of Propene + OH Reaction. Phys. Chem. Chem. Phys. 2014, 17, 2421-2431.

30. Khaled, F.; Giri, B. R.; Farooq, A. A High-Temperature Shock Tube Kinetic Study for the Branching Ratios of Isobutene + OH Reaction. Proc. Combust. Inst. 2017, 36, 265-272.

31. Bradley, J., Shock waves in physics and chemistry. Methuen, London 1962. 
32. Campbell, M. F.; Haylett, D. R.; Davidson, D. F.; Hanson, R. K. AEROFROSH: A Shock Condition Calculator for Multi-Component Fuel Aerosol-Laden Flows. Shock Waves 2016, 26, 429-447.

33. Vasudevan, V.; Davidson, D. F.; Hanson, R. K. High-temperature Measurements of the Reactions of $\mathrm{OH}$ with Toluene and Acetone. J. Phys. Chem. A. 2005, 109, 3352-3359.

34. Pang, G. A.; Hanson, R. K.; Golden, D. M.; Bowman, C. T. High-Temperature Measurements of the Rate Constants for Reactions of $\mathrm{OH}$ with a Series of Large Normal Alkanes: n-Pentane, n-Heptane, and n-Nonane. Z. Phys. Chem. 2011, 225, 1157-1178.

35. CHEMKIN-PRO, Reaction Design: San Diego, 2015.

36. Zhou, C.W.; Simmie, J. M.; Curran, H. J. Ab Initio and Kinetic Study of the Reaction of Ketones with $\mathrm{OH}$ for $\mathrm{T}=500-2000 \mathrm{~K}$. Part I: hydrogen-abstraction from $\mathrm{H}_{3} \mathrm{CC}(\mathrm{O}) \mathrm{CH}\left(3^{-}\right.$ $\left.{ }_{x}\right)\left(\mathrm{CH}_{3}\right)_{x}, x=0$ - 2. Phys. Chem. Chem. Phys. 2011, 13, 11175-11192.

37. Kwok, E. S. C.; Atkinson, R. Estimation of Hydroxyl Radical Reaction Rate Constants for Gas-phase Organic Compounds Using a Structure-Reactivity Relationship: An Update. Atmos. Environ. 1995, 29, 1685-1695.

38. Lam, K. Y.; Davidson, D. F.; Hanson, R. K. High-temperature Measurements of the Reactions of $\mathrm{OH}$ with a Series of Ketones: Acetone, 2-butanone, 3-pentanone, and 2-pentanone. J. Phys. Chem. A. 2012, 116, 5549-5559.

39. Badra, J.; Elwardany, A. E.; Farooq, A. Reaction Rate Constants of H-abstraction by OH from Large Ketones: Measurements and Site-specific Rate Rules. Phys. Chem. Chem. Phys. 2014, 16, 12183-12193.

40. Badra, J.; Elwardany, A.; Farooq, A. Shock Tube Measurements of the Rate Constants for Seven Large Alkanes Plus OH. Proc. Combust. Inst. 2015, 35, 189-196. 
41. Sivaramakrishnan, R.; Michael, J. V. Shock Tube Measurements of High Temperature Rate Constants for $\mathrm{OH}$ with Cycloalkanes and Methylcycloalkanes. Combust. Flame. 2009, 156, 1126-1134.

42. Tian, Z.; Fattahi, A.; Lis, L.; Kass, S. R. Cycloalkane and Cycloalkene C-H Bond Dissociation Energies. J. Am. Chem. Soc. 2006, 128, 17087-17092. 
TOC Graphic:

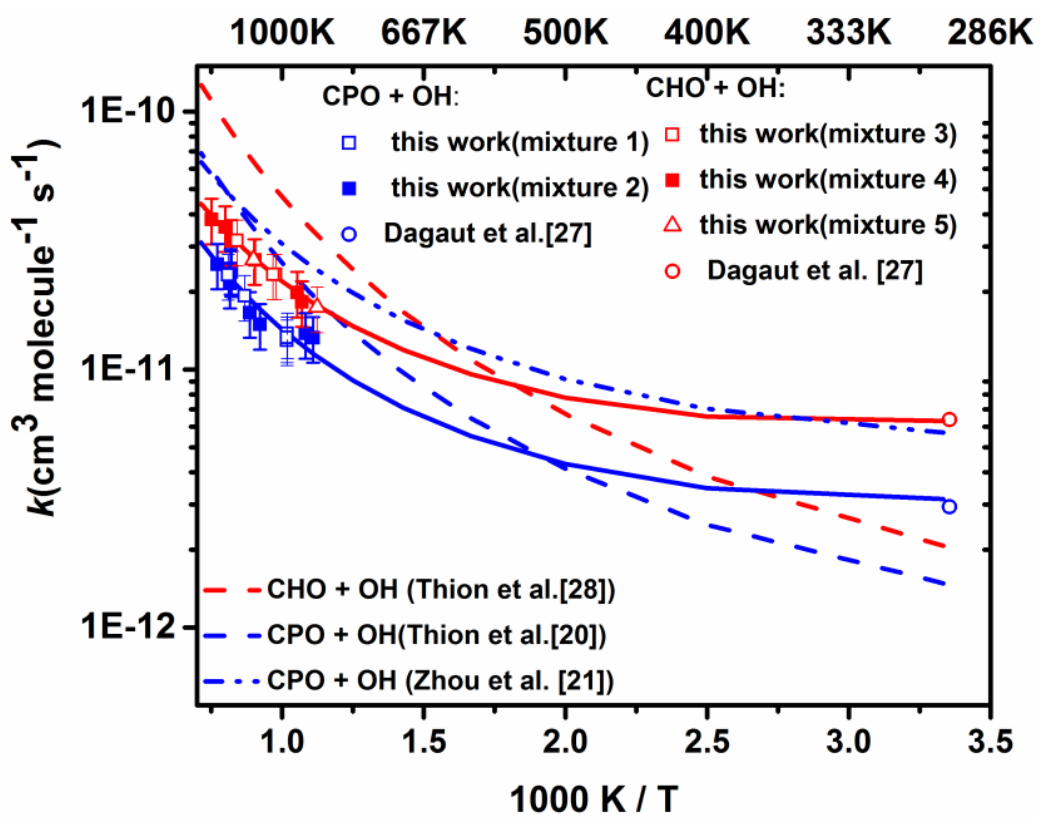

